OPEN ACCESS

Edited by:

Carlos M. Luquet,

Consejo Nacional de Investigaciones

Cientificas y Técnicas (CONICET),

Argentina

Reviewed by:

Gert Flik,

Radboud University Nijmegen,

Netherlands

Fabián Canosa,

CONICET Institute of Biotechnological

Research (IIB-INTECH), Argentina

*Correspondence:

Luis Fernando Marins dqmluf@furg.br

Specialty section:

This article was submitted to

Aquatic Physiology,

a section of the journal

Frontiers in Physiology

Received: 11 June 2021

Accepted: 04 August 2021

Published: 01 September 2021

Citation:

Meirelles MG, Nornberg BF,

da Silveira TLR, Kütter MT,

Castro CG, Ramirez JRB, Pedrosa V,

Romano LA and Marins LF (2021)

Growth Hormone Overexpression

Induces Hyperphagia and Intestinal

Morphophysiological Adaptations

to Improve Nutrient Uptake

in Zebrafish

Front. Physiol. 12:723853.

doi: 10.3389/fphys.2021.723853

\section{Growth Hormone Overexpression Induces Hyperphagia and Intestinal Morphophysiological Adaptations to Improve Nutrient Uptake in Zebrafish}

\author{
Marcela G. Meirelles ${ }^{1}$, Bruna F. Nornberg ${ }^{1}$, Tony L. R. da Silveira ${ }^{1}$, Mateus T. Kütter ${ }^{1}$, \\ Caroline G. Castro', Juan Rafael B. Ramirez ${ }^{2}$, Virgínia Pedrosa ${ }^{3}$, Luis Alberto Romano ${ }^{3}$ \\ and Luis Fernando Marins ${ }^{1 *}$ \\ ${ }^{1}$ Laboratório de Biologia Molecular, Instituto de Ciências Biológicas, Departamento de Ciências Fisiológicas, Universidade \\ Federal do Rio Grande - FURG, Rio Grande, Brazil, ${ }^{2}$ Laboratório de Bioquímica Funcional de Organismos Aquáticos, \\ Instituto de Oceanografia, Estação Marinha de Aquicultura, Universidade Federal do Rio Grande - FURG, Rio Grande, Brazil, \\ ${ }^{3}$ Laboratório de Imunologia e Patologia de Organismos Aquáticos, Instituto de Oceanografia, Estação Marinha \\ de Aquicultura, Universidade Federal do Rio Grande - FURG, Rio Grande, Brazil
}

The excess of circulating growth hormone $(\mathrm{GH})$ in most transgenic animals implies mandatory growth resulting in higher metabolic demand. Considering that the intestine is the main organ responsible for the digestion, absorption, and direction of dietary nutrients to other tissues, this study aimed to investigate the mechanisms by which gh overexpression modulates the intestine to support higher growth. For this purpose, we designed an 8-weeks feeding trial to evaluate growth parameters, feed intake, and intestinal morphometric indices in the adult gh-transgenic zebrafish (Danio rerio) model. To access the sensitivity of the intestine to the excess of circulating $\mathrm{GH}$, the messenger RNA (mRNA) expression of intestine GH receptors (GHRs) (ghra and ghrb) was analyzed. In addition, the expression of insulin-like growth factor 1a (igf1a) and genes encoding for di and tripeptide transporters (pept1a and pept1b) were assessed. Gh-transgenic zebrafish had better growth performance and higher feed intake compared to non-transgenic sibling controls. Chronic excess of $\mathrm{GH}$ upregulates the expression of its cognate receptor (ghrb) and the main growth factor related to trophic effects in the intestine (igf1a). Moreover, transgenic zebrafish showed an increased intestinal absorptive area and higher expression of crucial genes related to the absorption of products from meal protein degradation. These results reinforce the ability of GH to modulate intestinal morphology and the mechanisms of assimilation of nutrients to sustain the energy demand for the continuous growth induced by the excess of circulating $\mathrm{GH}$.

Keywords: gh-transgenic fish, Danio rerio, peptide transporter, feed intake, intestinal morphology 

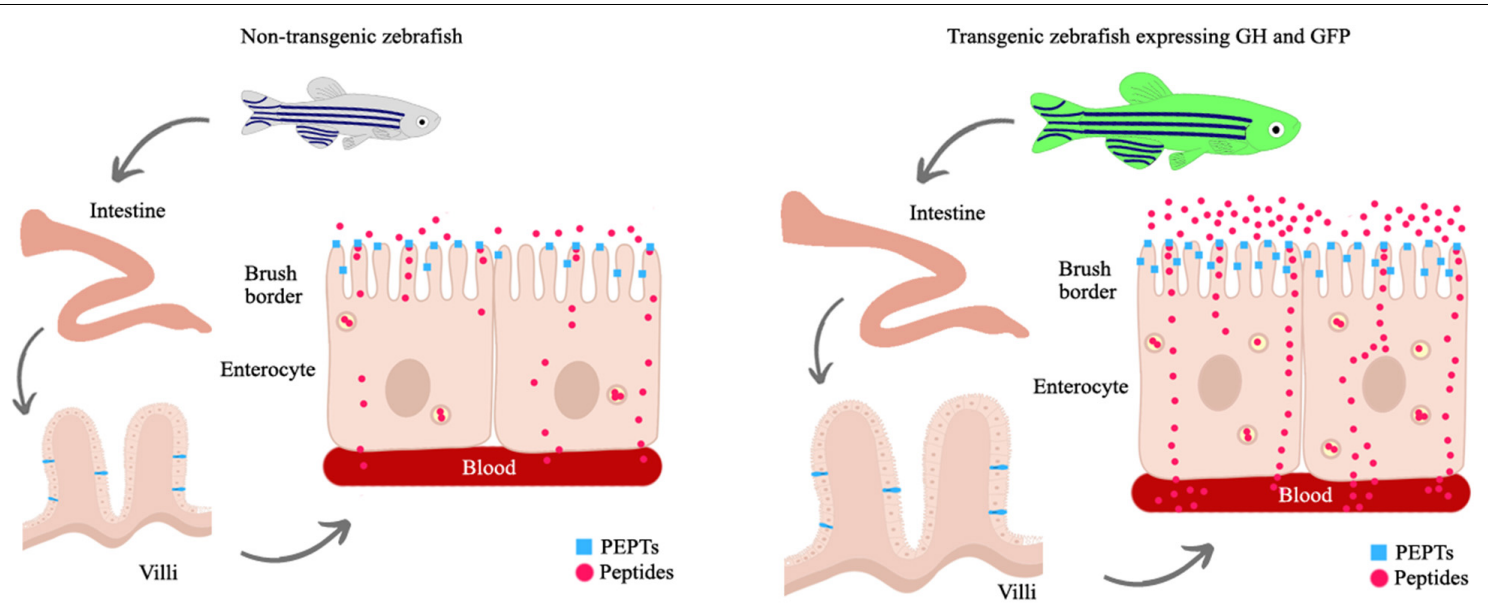

GRAPHICAL ABSTRACT | GH overexpression increases the intestinal mass and absorptive surface area both through the direct effects of GH transgenics (up-regulating the expression of its cognate receptor and insulin-like growth factor, igf1a) and through indirect effects through an increase in the amount of food consumed. In addition, hyperphagia provides a greater amount of nutrients in the intestinal lumen and stimulates the synthesis of di- and tri-peptide transporters, which are the main route of absorption of dietary products from protein degradation.

\section{INTRODUCTION}

Growth in fish is regulated through complex interactions among multiple organs and hormones that form the somatotrophic axis (White et al., 2016). This axis consists of growth hormone (GH), insulin-like growth factors (IGFs), and their corresponding membrane receptors and binding proteins (Fuentes et al., 2013; Ranke and Wit, 2018). However, the hormones that make up the somatotrophic axis have other functions that are not directly related to growth. GH in humans, for example, can act directly on sexual maturation, immune and cardiovascular systems, appetite control, neurogenesis, lipid, carbohydrate and mineral metabolism, amino acid absorption, and nitrogen retention, in addition to affecting aging (for review refer ( $\mathrm{Lu}$ et al., 2019)). To study the pleiotropic effects of GH, in 2007, the research group produced a transgenic zebrafish line (Danio rerio) that ubiquitously overexpresses GH (Figueiredo et al., 2007). Since then, we have been studying the effects of this overexpression on different biological systems of this model. It was shown that $g h$-transgenic zebrafish grew faster in a shorter period than their non-transgenic full sibling controls (Figueiredo et al., 2007; Rosa et al., 2010; Silva et al., 2015) and presented enhanced muscle hypertrophy when compared to non-transgenic fish (Kuradomi et al., 2011). GH overexpression also impacts oxidative metabolism (Rosa et al., 2008, 2011), aging (Rosa et al., 2010), reproduction (Figueiredo et al., 2013), ionic balance (Almeida et al., 2013), immune system (Batista et al., 2014), and appetite behavior (Dalmolin et al., 2015) in this $g h$-transgenic zebrafish line. Collectively, these findings provide evidence that the excess of circulating GH implies mandatory growth even in unfavorable conditions, resulting in higher metabolic demand.

Metabolic reorganization occurs in GH transgenic fish to meet their increased energy demands to improve growth and other physiological processes (Leggatt et al., 2009; White et al., 2016). It has long been known that the size, structure, and functional properties of the gastrointestinal (GI) tract of vertebrates may change to match the current functional demands (Starck, 2003). As the organ with one of the largest surface areas facing the environment (Spanier and Rohm, 2018), the intestine houses over 22 digestive enzymes and expresses over 53 channels, and transports proteins in its brush-border membrane (McConnell et al., 2011) for nutrient uptake. The dietary nutrients are essential for the construction of living tissues and they also are a source to supply energy for growth, reproduction, and health (Jia et al., 2017). In this regard, previous studies indicated that the growth and feed utilization of $g h$-transgenic salmon (Raven et al., 2006; Leggatt et al., 2009) and mice (Ulshen et al., 1993) were related to intestinal function. GH transgenesis influences differentially the utilization of dietary macronutrients (carbohydrates, protein, and lipids) for energy production (Leggatt et al., 2009). In the same way, it has been proposed that GH treatment enhanced transport/absorption of amino acids by the intestine of teleosts (Collie and Stevens, 1985; Sun and Farmanfarmaian, 1992; Farmanfarmaian and Sun, 1999; Walker et al., 2004), being these molecules the major energy substrates for the tissue of zebrafish (Jia et al., 2017). For teleosts, it has been proposed that $14-85 \%$ of the energy requirements is provided by amino acids depending on the stage of development (Van Waarde, 1983; Jia et al., 2017).

Although the transport of amino acids via the enterocyte plasma membrane is mediated by several classes of amino acid transporters, the transport of di and tripeptides is mediated by a single carrier system, called PEPT1 (Peptide Transporter 1) or SLC15A1 (solute carrier 15 family member A1) (for a review refer 27). In the 1990s, the intestinal oligopeptide transporter PEPT1 was cloned and characterized by various eukaryotes [reviewed by Spanier and Rohm (2018)]. Verri et al. (2003) described the molecular and functional characterization of the zebrafish PEPT1 transporter (Verri et al., 2003). As in mammals, PEPT1 is abundantly expressed particularly in the proximal intestine and provides highly effective transport of small peptides across 
the brush-border membrane of enterocytes (Verri et al., 2003, 2017; Vacca et al., 2019). The expression levels and functional activities of peptide transporters are affected by various factors, such as dietary composition, nutrient supply, developmental stage, physiological status, and hormones (Rubio-Aliaga and Daniel, 2008; Spanier, 2014; Spanier and Rohm, 2018), especially regarding the intestine. Significant effects of selected hormones on PEPT1 have been shown in the last decade. In mice, intestinespecific depletion of leptin signaling substantially reduced di and tripeptides uptake in the intestine (Tavernier et al., 2014). Insulin is also associated with the regulation of PEPT1 expression and function in rats and humans (Bikhazi et al., 2004). In fishes, there is evidence that leptin, cholecystokinin, and gastrin may have regulatory effects in intestinal peptide transport (Ostaszewska et al., 2010a,b; Koven and Schulte, 2012), but there is little information on the hormonal control of peptide absorption caused by supraphysiological levels of GH.

Since PEPT1 is the major route for the absorption of products from protein degradation after a meal (Spanier, 2014), many studies have investigated the functional plasticity of this class of proteins and how they functionally (co)operate to support growth in different animal models [for a review, refer Verri et al. (2017)]. Zebrafish is a model organism with extensive literature regarding their stomachless gut morphology and digestive tract development [reviewed by Wang et al. (2010) and Brugman (2016)]. While the human GI tract is divided into stomach, duodenum, jejunum, ileum, and colon, the zebrafish GI tract is generally subdivided into three distinct regions: intestinal bulb, midgut, and hindgut (Wang et al., 2010). However, how hormones such as GH interact with the GI tract still need to be studied. For this purpose, gh-transgenic fishes provide a powerful model to understand how chronic GH excess could regulate morphophysiological mechanisms in the intestine to maintain a higher growth rate and energy requirement. Thus, this study aimed to investigate the effects of $\mathrm{GH}$ overexpression on intestinal morphology, ultrastructure, and peptide transport in a transgenic zebrafish line.

\section{MATERIALS AND METHODS}

\section{Animals and Conditions}

The $g h$-transgenic zebrafish line used in this study was generated by Figueiredo et al. (2007). The transgenic and non-transgenic zebrafish were obtained by crossbreeding between the F0104 line and wild zebrafish. In addition to $g h$ transgene, the $g h$ transgenic zebrafish expresses the green fluorescent protein (GFP) as a transgenesis tag (Figure 1). The non-transgenic zebrafish were siblings of the transgenic zebrafish which did not incorporate the genetic construct into their genome. All the procedures involving animals were conducted in accordance with the Brazilian Guidelines for the Care and Use of Animals for Scientific and Educational Purposes and were approved by the Ethics Committee of the Federal University of Rio Grande (FURG) - Brazil (Protocol: 23116.008403/2018-32).

Gh-transgenic and non-transgenic zebrafish groups were kept in a recirculating aquaculture system. A total of 80

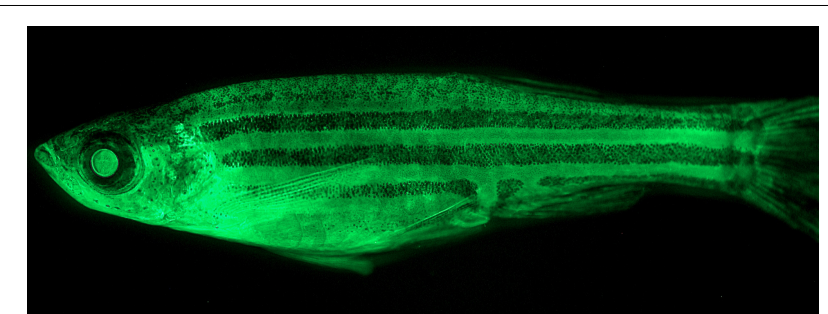

FIGURE 1 | Gh-transgenic zebrafish (Danio rerio). The F0104 line was developed from the co-injection of two separate transgenes, both containing the carp $\beta$-actin promoter (Cyprinus carpio), which controls the expression of the GFP gene from the jellyfish Aequorea victoria or the $\mathrm{GH}$ gene from the marine silverside fish (Odonthestes argentinensis). Linearized transgenes were co-injected in an equimolar ratio into zebrafish zygotes to provide the same genome integration and expression (Figueiredo et al., 2007). In the F0104 line, GFP expression works not only as a marker of transgenesis but also allows mapping the tissues that are expressing $\mathrm{GH}$ since both GFP and $\mathrm{GH}$ are under the control of the same gene promoter.

zebrafish 7-month-old, of both sexes (40 transgenic and 40 nontransgenic full siblings) were raised in eight tanks containing $15 \mathrm{~L}$ of water (four tanks/group and 10 animals/tank). Ghtransgenic zebrafish co-expressing GFP were identified under an epifluorescence microscope and placed in a separate tank. The tanks were connected to a filter tank filled with zeolite, bioceramic, and ultraviolet (UV) lamp, and a heater thermostat. The photoperiod was adjusted to $14: 10 \mathrm{~h}$, light/dark period. Management and maintenance of zebrafish complied with the Zebrafish Book ${ }^{1}$. During the breeding period, the water temperature was maintained at $27.2 \pm 0.3^{\circ} \mathrm{C}$. The water $\mathrm{pH}$ $(7.5 \pm 0.1)$ and dissolved oxygen $\left(>6 \mathrm{mg} \mathrm{L}^{-1}\right)$ were measured daily. Water quality parameters were measured once a week using commercial kits (Labcon Ammonia Alcon Fresh Water; Labcon Test Nitrite Alcon, Brazil). Total ammonia and nitrite levels were maintained lower than 0.5 and $0.25 \mathrm{mg} \mathrm{L}^{-1}$, respectively. The tanks were scrubbed, debris and feces siphoned out, and $25 \%$ of the water changed every 3 days. Until the start of the experiment, fish were fed two times a day (5 days a week) ad libitum with commercial feed (Tetra ColorBits, Germany, $47.5 \%$ crude protein). For the analysis of feed intake, a predetermined amount of feed was weighed and offered in small portions to the fish until they stopped feeding for at least $2 \mathrm{~min}$. The remaining feed was weighed again and the difference was considered as feed consumed. This approach allowed us to estimate the amount of feed that a group of fish was able to ingest at each feeding event during the experimental period.

\section{Growth Parameters and Tissue Collection}

From day 0 to day 60, every 15 days, fish were anesthetized (buffered tricaine methanesulfonate MS-222, pH 7.2, SigmaAldrich, United States, $100 \mathrm{mg} \mathrm{L}^{-1}$ ), individually weighed (mg) and measured in lateral decubitus for standard length $(\mathrm{cm})$. Throughout the 60-day feeding trial, animals were hand-fed to

\footnotetext{
${ }^{1}$ https://www.zfin.org
} 
apparent satiety three times a day. At the end of the experiment, fish were euthanized using an overdose of buffered MS-222 at $400 \mathrm{mg} \mathrm{L}^{-1}$. Fish were then dissected and samples of the whole intestine were individually removed, weighed (mg), and measured in length $(\mathrm{cm})$. After this, samples were immediately stored for histological and gene expression analysis. For tissue fixation, the fish were fasted for $24 \mathrm{~h}$ to clean the intestinal contents. It should be mentioned in this study that the sampling was performed in a single day. The whole process took $<5 \mathrm{~h}$.

Growth performance indicators were measured, such as weight gain $(\mathrm{mg})$, standard body length $(\mathrm{cm})$, feed intake $(\mathrm{mg})$, specific growth rate (SGR), enterosomatic index (ESI), and intestinal quotient (IQ), using the following formulas:

$$
\begin{aligned}
& \text { Weight gain }=\text { Final weight }- \text { Initial weight; } \\
& \text { SGR }=([\text { Ln Final weight }- \text { Ln Initial weight } / t] \times 100) \\
& \text { ESI }=([\text { intestinal weight } / \text { body mass }] \times 100) ; \\
& \text { IQ = ([intestinal length/standard length }] \times 100)
\end{aligned}
$$

\section{Histological Analysis}

Intestines ( $n=18$ samples per group) were histologically evaluated in paraffin-embedded tissue sections stained with Periodic acid-Schiff (PAS), Alcian blue, and hematoxylin and eosin (H\&E). For morphometry, longitudinal sections (about 5 $\mu \mathrm{m}$ ) were evaluated using brightfield microscopy (Primo Star, Zeiss, Germany) and the micrographs obtained with the Zen software (Axion Vision 4.8.2.0, Carl Zeiss, Germany). Intestinal folds were counted in the entire intestine in six fields randomly sampled on PAS-stained slides ( $\times 10$ magnification, Figure 2A). Representative intestinal goblet cell number was determined by counting cells in the anterior and middle intestine in six fields randomly sampled on Alcian blue-stained slides $(\times 20$ magnification, Figure 2B). Mean villus height and width $(\times 40$ magnification, Figure $2 \mathrm{C})$ and mean enterocyte length $(\times 40$ magnification, Figures 2D,D), were measured in the anterior and middle intestine on PAS-stained slides with a minimum of 24 villi averaged per fish to make $n=1$. All the measurements were taken from micrographs using Software ImageJ (Abràmo et al., 2004) and performed by calibrated and blinded analyzers.

\section{Morphometric Analysis by Transmission Electron Microscopy}

For morphometric transmission electron microscopy (TEM) analysis, the anterior segment of each intestine was used since this region is considered to be the main site of nutrient absorption in teleost fishes (Løkka et al., 2013; Faccioli et al., 2016). Fragments of the anterior intestine ( $n=6$ samples per group) were fixed for $48 \mathrm{~h}$ at $4^{\circ} \mathrm{C}$ in a solution of $6 \%$ paraformaldehyde, $3 \%$ glutaraldehyde in phosphate buffer ( $\mathrm{pH} 7.4)$ to analyze the morphometry of intestinal microvilli. The samples were then post-fixed for $2 \mathrm{~h}$ in $2 \%$ osmium tetroxide $+0.4 \mathrm{M}$ sodium cacodylate $(\mathrm{pH} 7.4$, in the proportion of 1:1), dehydrated in a graded ethanol and acetone series, and later embedded in Araldite resin. Ultra-thin sections $(60-80 \mathrm{~nm})$ were mounted on copper grids and contrasted with uranyl acetate and lead citrate (Reynold's solution). Analysis and photographic documentation were performed with an EM 900 ZEISS transmission electron microscope (Zeiss, Germany).

Images of intestinal epithelium ( $n=15$ micrographs of each sample) were used for measurements of height $(H)$ and diameter (D) of the microvilli (for a total of 225 microvilli averaged per fish to make $n=1$ ), using the Software ImageJ (Abràmo et al., 2004). With the above data, the microvilli surface area was calculated in the following formula: $\mu \mathrm{m}^{2}=\left([H \pi D]+\left[\pi R^{2}\right]\right)$, where $R=0.5 \mathrm{D}$ (Faccioli et al., 2016). Calibrated and blinded analyzers performed all measurements.

\section{RNA Extraction and Complementary DNA Synthesis}

Nine individuals of each group were randomly sampled for gene expression analysis. Total RNA was extracted from the intestine using TRIzol Reagent (Invitrogen, Brazil), following the protocols from the manufacturer. RNA was treated with DNAse I Amplification Grade (Invitrogen, Brazil) to remove genomic DNA contamination. RNA quality and quantity were determined by spectrophotometry using a BioDrop (Isogen Life Science, B.V, Veldzigt, Netherlands). RNA integrity was assessed through electrophoresis on 1\% agarose gel. Complementary DNA (cDNA) was synthesized from $1 \mu \mathrm{g}$ of total RNA using a High Capacity cDNA Reverse Transcription (Applied Biosystems, São Paulo, Brazil) according to the recommendation from the manufacturer.

\section{Gene Expression Analyses by Quantitative Reverse Transcription Polymerase Chain Reaction}

Quantitative reverse transcription polymerase chain reactions (qRT-PCRs) were performed with the SYBR green method in a 7500 Real-Time System (Applied Biosystems, MA, United States). The preliminary tests with standard dilution curves of cDNA showed that all primers used had efficiencies close to $98 \%$. Each qRT-PCR reaction was performed in a $15 \mu \mathrm{l}$ mixture contained $1.2 \mu l$ diluted cDNA, $7.5 \mu$ l Power-Up ${ }^{\text {TM }}$ SYBR Green Master $\mathrm{Mix}^{\mathrm{TM}}$ (Thermo Fisher Scientific, São Paulo, Brazil), $0.375 \mu \mathrm{l}$ forward and reverse each gene-specific primer, and $5.55 \mu l$ nuclease-free water. Duplicate PCRs were carried out for each sample. The amplification conditions were $95^{\circ} \mathrm{C}$ for $10 \mathrm{~min}, 40$ cycles at $95^{\circ} \mathrm{C}$ for $15 \mathrm{~s}$, and $60^{\circ} \mathrm{C}$ for $1 \mathrm{~min}$. The melting curves of amplified products were generated to ensure the specificity of assays at the end of each qRT-PCR. In this study, three candidate reference genes (elongation factor 1 alpha, eef $1 \alpha ; \beta$-actin, actb1; and acidic ribosomal protein, rpl13a) were tested using geNorm VBA applet for Microsoft Excel (Vandesompele et al., 2002). The most stable genes were eef $1 \alpha$ and $r p 113 a$, which were selected as reference genes, in accordance with Rassier et al. (2020). The details on primer sequences and efficiency used in the present study are provided in Table 1 . Reference and target genes expression was evaluated by the relative quantification method (Pfaffl, 2001).

\section{Data Analysis}

All data are presented as mean \pm SD. Data were tested for normality using Shapiro-Wilk's test and homogeneity of 


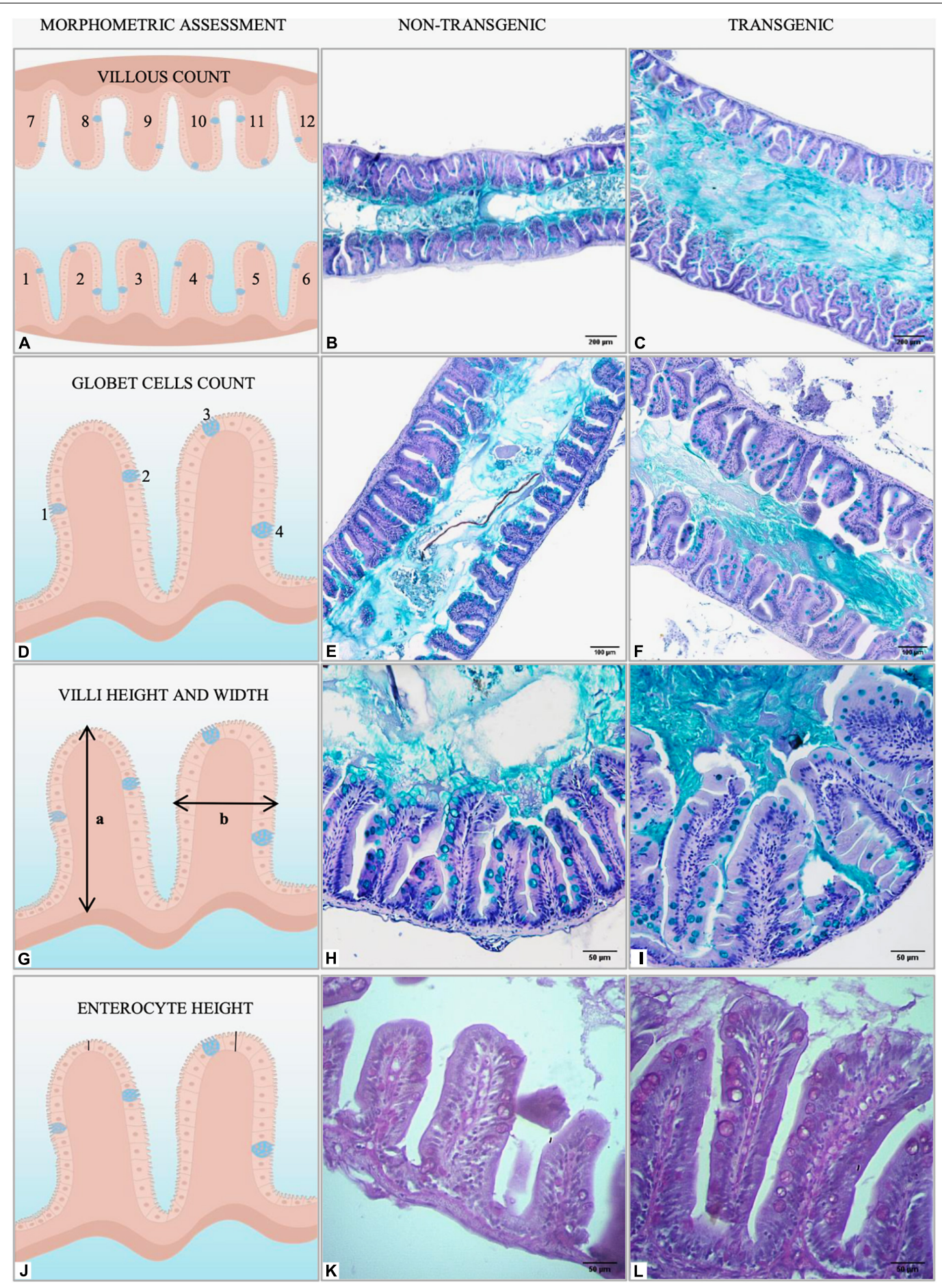

FIGURE 2 | Graphical representation of morphometric analysis performed in the intestine of non-transgenic and gh-transgenic zebrafish (D. rerio) siblings. (A) Intestinal folds were manually counted in six fields randomly sampled for each animal using the multipoint tool from ImageJ. Representative Alcian blue-stained sections of midgut cross-sections from (B) non-transgenic and (C) gh-transgenic zebrafish. Magnification: $\times 10$, scale bar: $200 \mu \mathrm{m}$. (D) The number of intestinal goblet cells was determined by manually counting all cells in six randomly sampled fields for each animal using the multipoint tool from ImageJ. Representative images of midgut sections stained for the goblet cell marker Alcian blue from (E) non-transgenic and (F) gh-transgenic zebrafish. Magnification: $\times 20$, scale bar: 100 $\mu \mathrm{m}$. (G) Intestinal villus height (a) and width (b) were manually measured in the anterior and middle intestine from 24 individual villi randomly sampled for each animal using the segmented line tool from ImageJ. Representative Alcian blue-stained sections of anterior intestine from (H) non-transgenic and (I) gh-transgenic zebrafish. Magnification: $\times 40$, scale bar: $50 \mu \mathrm{m}$. (J) Enterocyte height was manually measured in the anterior intestine from 24 individual villi randomly sampled for each animal using the segmented line tool from ImageJ. Representative Periodic acid-Schiff (PAS) stained sections of anterior intestine from (K) non-transgenic and (L) gh-transgenic zebrafish. Magnification: $\times 40$, scale bar: $50 \mu \mathrm{m}, n=18$ non-transgenic and $18 \mathrm{gh}$-transgenic zebrafish. 
TABLE 1 | Gene-specific primers were used for quantitative reverse transcription polymerase chain reactions (qRT-PCR).

\begin{tabular}{|c|c|c|c|c|c|}
\hline Gene & Primer sequence $\left(5^{\prime}-3^{\prime}\right)$ & $\mathbf{R}^{2}$ & Efficiency (\%) & Amplicon Size (bp) & Accession no. \\
\hline \multirow[t]{2}{*}{ igf1a } & F: CAGGCAAATCTCCACGATCTC & 0.99 & 100 & 61 & NM_131825.2 \\
\hline & R: TाTGGTGTCCTGGGAATATCTGT & & & & \\
\hline \multirow[t]{2}{*}{ Ghra } & F: TGCTGTGCGCTACAAAATGG & 0.97 & 93 & 62 & NM_001083578.1 \\
\hline & R: GCTTCTGCAAAGGCTGATAGAAA & & & & \\
\hline \multirow[t]{2}{*}{ Ghrb } & F: GAACTCAGAGTCCGGGCAAA & 0,98 & 97 & 117 & NM_001111081.2 \\
\hline & R: AAAGACCAGCACAGCCGTAA & & & & \\
\hline \multirow[t]{2}{*}{ slc15a1a } & F: GGC TTC GGT TCC TCC TAC AC & 0.98 & 97 & 96 & XM_021478814.1 \\
\hline & R: CGA GTT GGG CTG CAT GTC TT & & & & \\
\hline \multirow[t]{2}{*}{ slc15a1b } & F: GCA TCT ACG CAA AGC AGA GC & 0.99 & 98 & 73 & NM_198064.1 \\
\hline & R: ATG AGG GCA ACC ACC ATG AG & & & & \\
\hline \multirow[t]{2}{*}{ slc15a2 } & F: CAC AGC CGG AGA AGT CAT GT & 0.99 & 98 & 80 & NM_001039828.1 \\
\hline & R: GAA CGG ATT TCA TGC TCG CC & & & & \\
\hline \multirow[t]{2}{*}{ actb1 } & F: GCTGTITCCССTCCATTGTT & 0.99 & 97 & 60 & NM_131031.2 \\
\hline & R: TCCCATGCCAACCATCACT & & & & \\
\hline \multirow[t]{2}{*}{ ef1 $\alpha$} & F: GGGCAAGGGCTCCTTCAA & 0.99 & 99 & 54 & NM_131263.1 \\
\hline & R: CGCTCGGCCTTCAGTTTG & & & & \\
\hline \multirow[t]{2}{*}{ rp/13a } & F: TCTGGAGGACTGTAAGAGGTATGC & 0.99 & 99 & 148 & NM_212784.1 \\
\hline & R: AGACGCACAATCTTGAGAGCAG & & & & \\
\hline
\end{tabular}

variance using Levene's and Bartlett's tests. Data that did not meet the assumptions of variance and normality were logtransformed prior to further analysis. Body weight against time was linearly modeled, and the slopes of the two groups were statistically compared to determine growth differences. ANOVA with multiple comparisons was performed between genotypes at each time for weight gain and body length. A twotailed independent $t$-test was performed in the other measured parameters between the two groups. Significant differences were determined with a $p<0.05$. All statistical tests were performed using GraphPad Prism 7.0 (San Diego, CA, United States).

\section{RESULTS}

\section{Growth Performance}

Over the 8-week growth analysis, significant growth response was detected in adult $g h$-transgenic zebrafish compared to nontransgenic siblings (Figure 3). The transgenic group expressed the phenotype attributed by the transgenesis, being statistically heavier (slopes $4.056 \pm 0.40$ and $2.862 \pm 0.13 ; R^{2} 0.8472$ and 0.9620, T and NT, respectively; $p<0.001$ ) and longer $(p<0.0001)$ (Figures 3A,B, respectively) in comparison to the body mass and length of the non-transgenic group. At the start of the trial, non-transgenic and gh-transgenic adult zebrafish weighed $195.82 \pm 6.31 \mathrm{mg}$ and $240.95 \pm 17.12 \mathrm{mg}$, while at the end of the experiment they weighted $369.07 \pm 18.33 \mathrm{mg}$ and $489.65 \pm 24.55 \mathrm{mg}$, respectively (Figure 3A). The nontransgenic group presented $2.79 \pm 0.03 \mathrm{~cm}$ and the transgenic group presented $3.15 \pm 0.04 \mathrm{~cm}$ of length at the end of the experiment (Figure 3B). SGR showed a better performance in $g h$ genotype compared to controls $(1.237 \pm 0.04$ and $1.060 \pm 0.04$, respectively, $p<0.05$ ) (Figure 3C). Additionally, repeated ANOVA measures detected differences in weight gain in favor of the transgenic group $(p<0.01)$. However, multiple comparisons did not detect differences in 45 days (Figure 3D). Feed intake was increased by 1.8 -fold in transgenic group $(p<0.01)$ (Figure $3 \mathbf{E}$ ). No significant mortalities were observed during the whole experiment (2 NT and $3 \mathrm{~T}$ fish).

\section{Intestinal Morphometrical Assessment}

$G$-transgenic zebrafish had longer intestine $(p<0.001)$ (Figure 4A). The non-transgenic group presented $2.36 \pm 0.06 \mathrm{~cm}$ and the transgenic group presented $2.58 \pm 0.06 \mathrm{~cm}$ of intestinal length. However, no significant difference was observed for IQ between the groups (data not shown), demonstrating that the increased intestine length in gh group was proportional to the increased in standard body length. Also, gh-transgenic fish had significantly heavier intestinal mass $(\mathrm{NT}=9.35 \pm 5.70 \mathrm{mg}$ and $T=17.61 \pm 8.28 \mathrm{mg}, p<0.001)$ and ESI $(\mathrm{NT}=2.87 \pm 0.66 \mathrm{mg}$ and $T=3.61 \pm 0.77 \mathrm{mg}, p<0.05$ ) (Figures $4 \mathrm{~B}, \mathrm{C}$, respectively).

As in mammals, the ultrastructure of the digestive tract has allowed us to infer about absorption of nutrients in fish (Zeng et al., 2014; Faccioli et al., 2016). In this sense, we investigate phenotypic modifications related to micro and ultrastructure in the intestine of the gh-transgenic zebrafish. In the histological assessment, villus length $(T=179.06 \pm 27.42$ $\mu \mathrm{m}$ and $\mathrm{NT}=138.68 \pm 22.43 \mu \mathrm{m} ; p<0.0001)$, villus width $(T=62.93 \pm 7.15 \mu \mathrm{m}$ and $\mathrm{NT}=54.44 \pm 5.71 \mu \mathrm{m}$; $p<0.0001)$, and length of enterocyte $(T=36.63 \pm 3.67 \mu \mathrm{m}$ and $\mathrm{NT}=22.12 \pm 2.95 \mu \mathrm{m} ; p<0.0001)$ were significantly higher in $g h$-transgenic zebrafish compared to those present in the intestine epithelium of control group (Figures $2 \mathbf{H}, \mathbf{I}, \mathbf{K}, \mathbf{L}, \mathbf{4 D}-\mathbf{F}$, respectively). However, the number of intestinal folds and goblet cells was not significantly affected $(p>0.05)$ (data not shown).

For the TEM analysis, the height and diameter of microvilli and the microvillus surface area did not vary between the groups $(p>0.05)$ (data not shown). Images showed no difference in the 

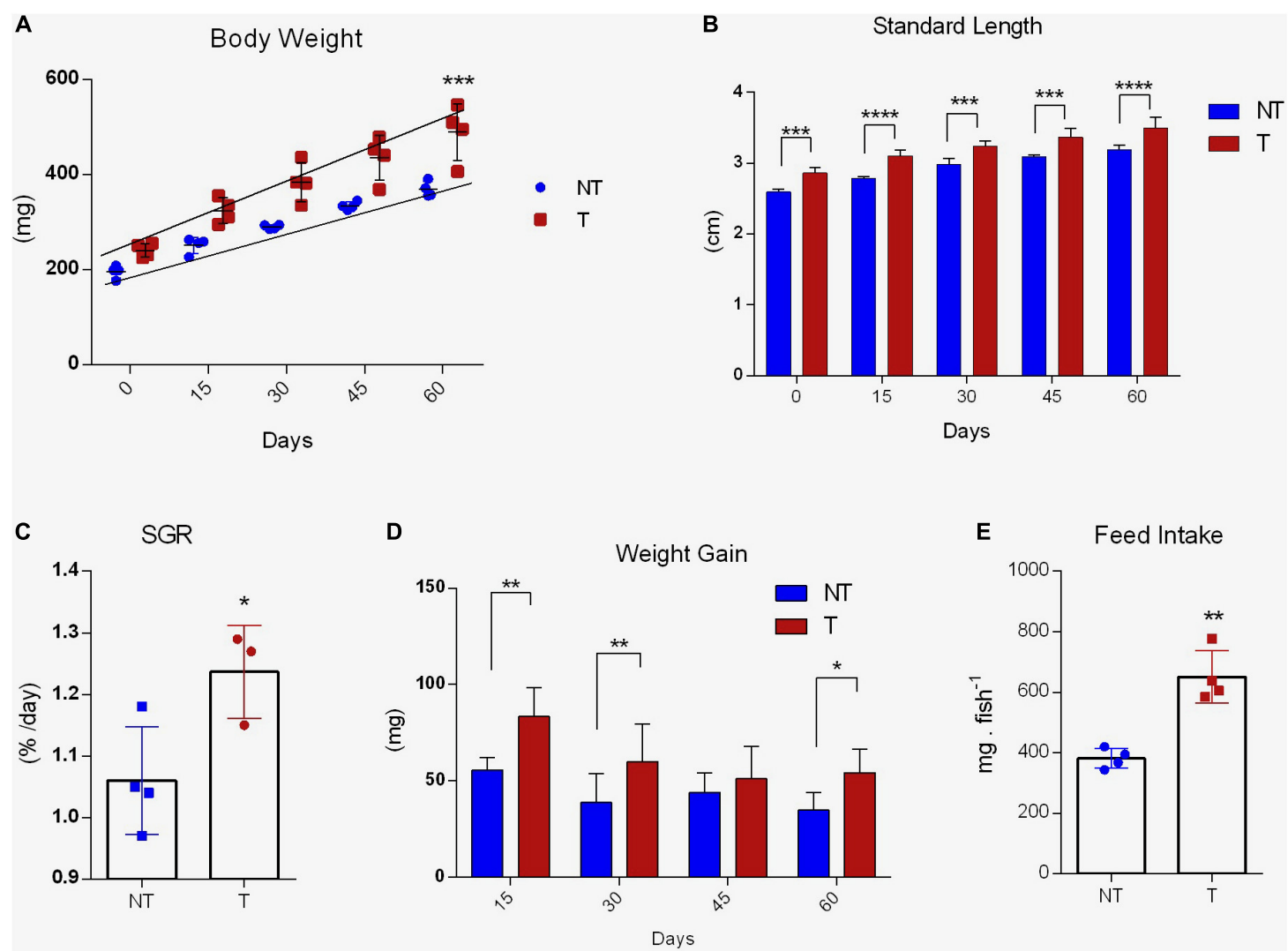

FIGURE 3 | Growth performance and feed intake of gh-transgenic zebrafish (D. rerio). Body weight (A), length (B), SGR (C), weight gain (D), and feed intake (E) were significantly increased in response to $\mathrm{GH}$ excess in transgenic zebrafish compared to non-transgenic full siblings. Weight (mg) and length (mm) were measured every 15 days during the 60-day growth experiment (non-transgenic, $n=38$, and gh-transgenic fish, $n=37$ ). Differences in body weight between the two groups were determined by linear regression analysis. ANOVA with multiple comparisons was performed between the two genotypes at each time point for weight gain and body length. Comparisons of SGR and feed intake between two groups were taken by a two-tailed $t$-test. Data are shown as means \pm SE of 37 fish per group. Asterisks indicate significant differences $\left({ }^{\star} p<0.05 ;{ }^{\star \star} p<0.01 ;{ }^{* \star \star} p<0.001\right.$; and ${ }^{\star \star \star \star} p<0.0001$ ). Zebrafish that overexpress GH exhibited a linear increase in growth $(p<0.05)$. gh, growth hormone gene; NT, Non-Transgenic; T, Transgenic.

microvillus morphology in both intestine of control (Figure 5A) and transgenic fish (Figure 5B).

\section{Differential Gene Expression}

To evaluate the intestine GH sensitivity of zebrafish, the expression of GHR was analyzed. Two paralogs of GHR have been defined in zebrafish based on their similarity: ghra and ghrb (Di Prinzio et al., 2010). Our data show that the transcriptional level of $g h r b$ was significantly increased $(p<0.01)$ in the intestine of transgenic fish (Figure 6A), but the isoform ghra did not differ significantly $(p>0.05)$ between the groups (data not shown). Resembling ghrb, igfla levels were higher $(p<0.05)$ in $g h$-transgenic intestine (Figure 6B).

Further, it was analyzed whether $g h$ transgenesis could change the mRNA expression of genes related to transcellular transport of di and tripeptides in the intestine. According to Vacca et al. (2019), zebrafish PepT1a (slc15a1a) and PepT1b (slc15a1b) amino acid sequences shared $78 \%$ similarity and $62 \%$ identity. In this study, the levels of slc15a1a and slc15a1b transcripts were significantly increased ( $p<0.01$ and 0.0001 , respectively) in $g$-transgenic fish compared to controls (Figures 6C,D, respectively). No significant differences $(p>0.05)$ were noted in the transcriptional level of $\operatorname{slc} 15 a 2$.

\section{DISCUSSION}

In this study, we used a transgenic zebrafish model that overexpresses $g h$ to investigate whether the excess of circulating $\mathrm{GH}$ could be related to changes in the morphology/ultrastructure of the intestine and molecular targets associated with absorption of dietary nutrients. Taking into account, it is already known that excess GH leads to an increase in food intake, we hypothesize that the intestine may adapt to this situation not only by changing its size but also by increasing the number of small peptide transporters, such as a strategy to increase energy uptake imposed by excess circulating $\mathrm{GH}$.

Even though zebrafish has limited growth (Mommsen, 2001; Biga and Goetz, 2006), gh-overexpression in fish from the F0104 line was able to increase $31 \%$ in weight and $11.4 \%$ in standard length compared to non-transgenic siblings. These 

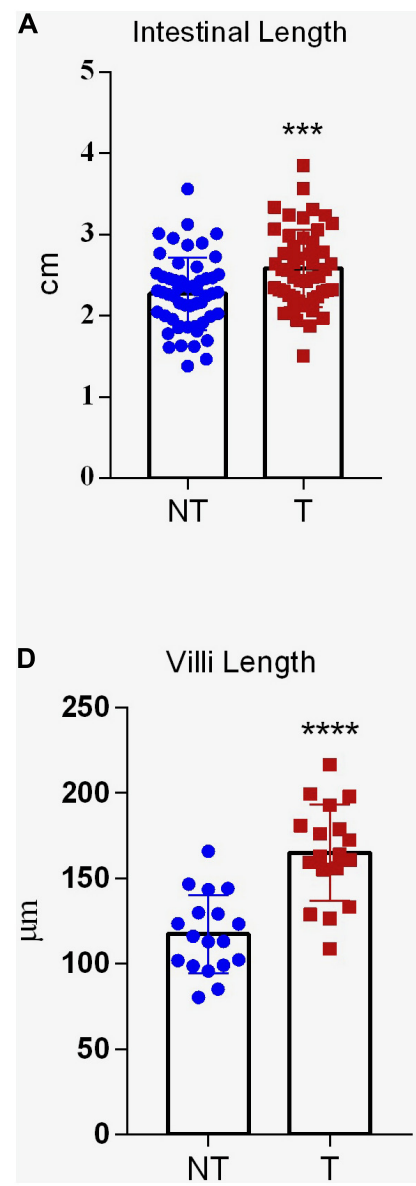

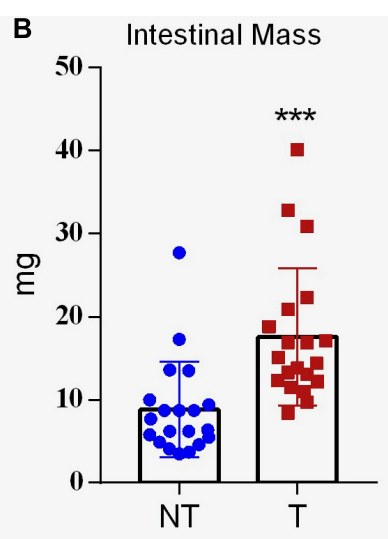

E

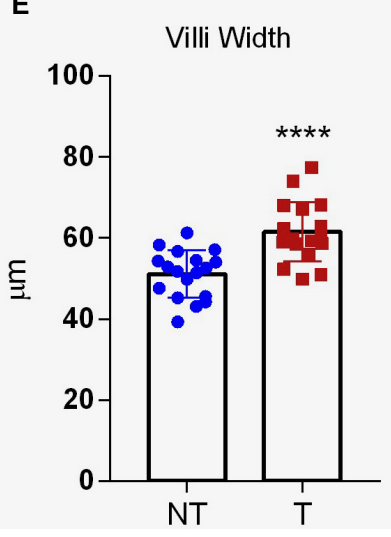

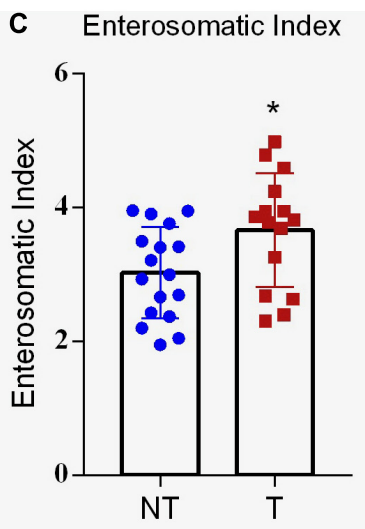

$\mathbf{F}$

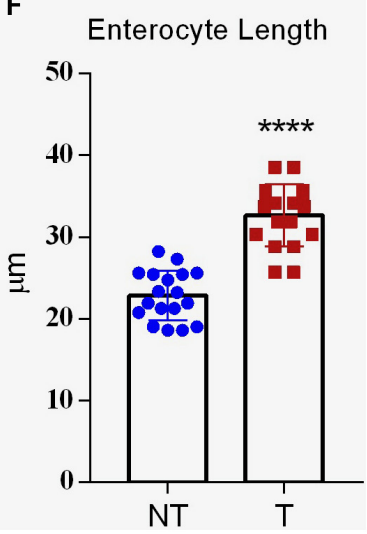

FIGURE 4 | Intestinal absorptive area of gh-transgenic zebrafish (D. rerio). Intestinal length (A), intestinal mass (B), and enterosomatic index (ESI) (C) were significantly increased in response to GH excess in transgenic zebrafish compared to non-transgenic full siblings. Data are shown as means \pm SE of 37 fish per group. Gh-transgenic zebrafish show a significantly enhancement of villus height (D), villus width (E), and length of enterocyte (F) with respect to the control. Differences in all intestinal parameters between the two groups were determined using a two-tailed $t$-test. Data are shown as mean \pm SE of 18 fish per group. Asterisks indicate significant differences $\left({ }^{*} p<0.05 ;{ }^{\star \star \star} p<0.001\right.$; and $\left.{ }^{\star \star \star \star} p<0.0001\right)$. NT, non-transgenic; T, transgenic.

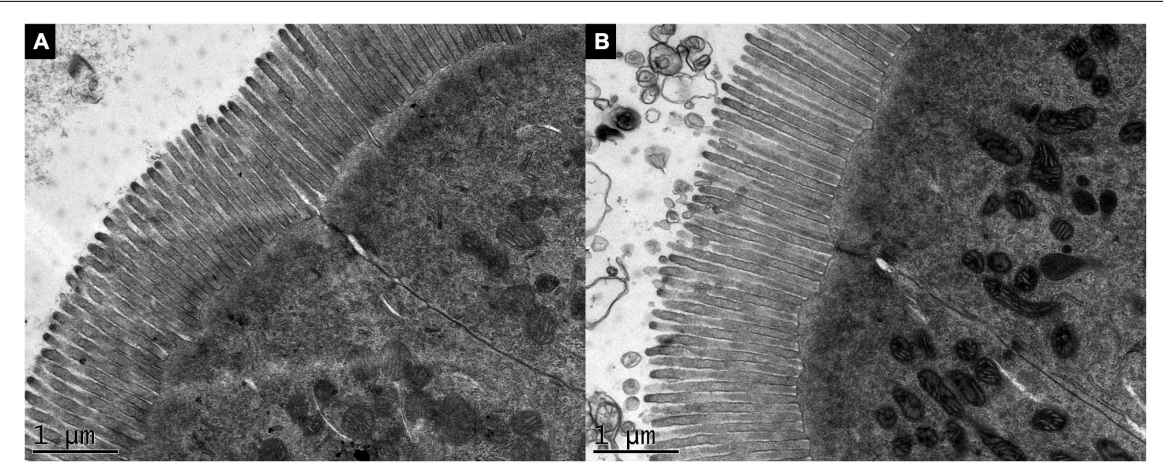

FIGURE 5 | Ultrastructure of the intestinal microvilli of gh-transgenic zebrafish (D. rerio). Electron micrographs show organized microvilli on the apical surface in the enterocyte of non-transgenic (A) and gh-transgenic zebrafish (B) siblings. No difference in surface area of microvillus from the anterior intestine was detected between the groups $(p>0.05)$. Magnification: $\times 25.000$, scale bar: $1 \mu \mathrm{m}$.

findings reinforce that transgenesis for $g h$ leads to a higher level of energy required to support body growth. In addition, GH exerts its physiological actions by binding to its cognate receptor in target tissues, and such interaction depends on its affinity and the density of the receptor on the cell membrane (Ranke and Wit, 2018). In this context, we first investigated whether 


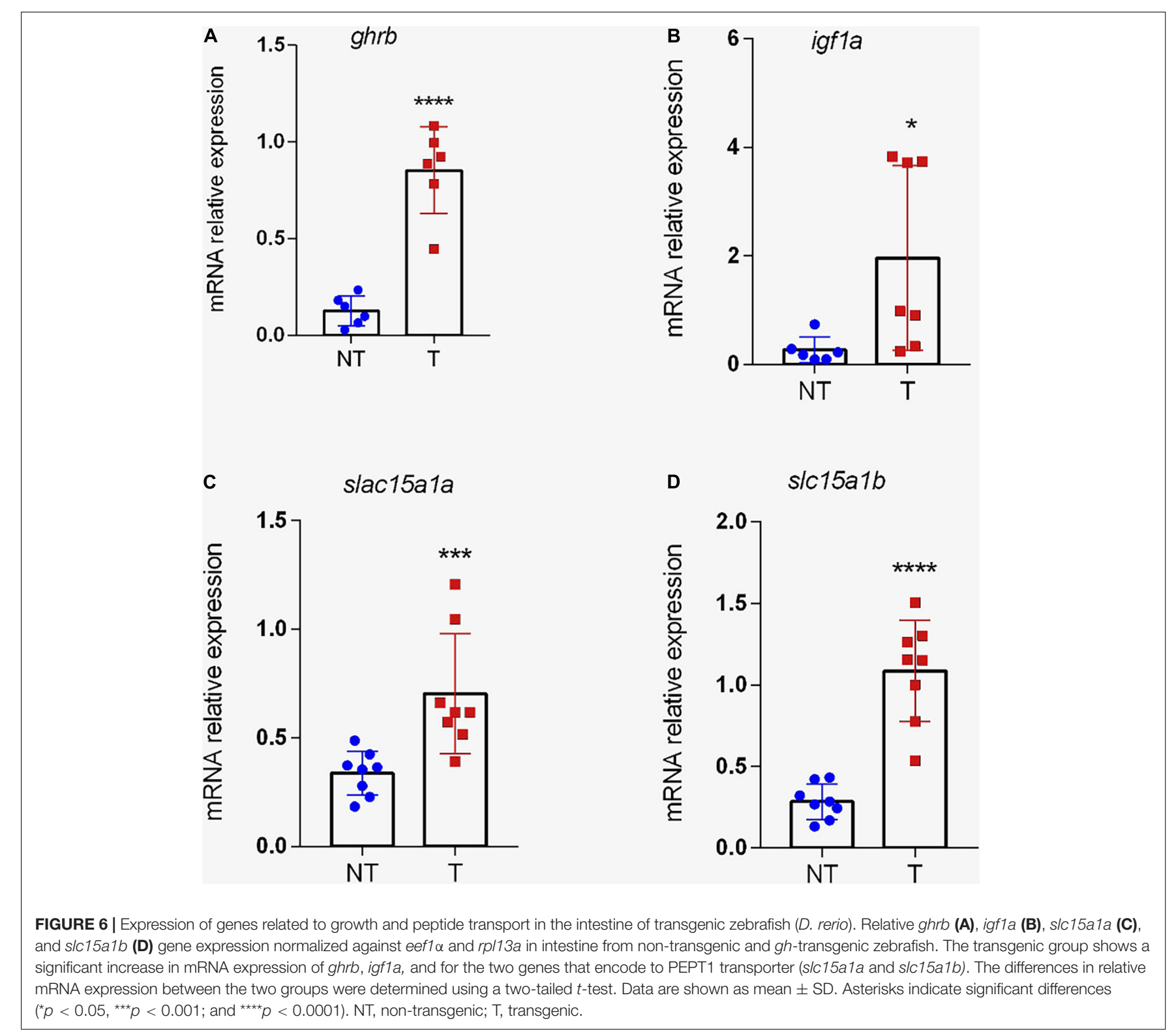

$g h$ overexpression could alter the expression of its receptor in intestinal cells. Intestinal mRNA expression of ghrb was significantly increased in $g h$-transgenic zebrafish. The expression of both ghra and ghrb in intestine was reported in many fish species (Jiao et al., 2006; Li et al., 2007; Fuentes et al., 2008). Di Prinzio et al. (2010) showed that both $g h r$ paralogs were predominantly expressed in the intestine and liver of adult zebrafish. In parallel, in situ hybridization analysis revealed that $g h r b$ transcript was localized in the zebrafish intestine at $30 \mathrm{~h}$ postfertilization (hpf) (Di Prinzio et al., 2010) that suggests the role of $\mathrm{GH}$ in the development of this tissue. In addition, the metabolic state and the availability of external nutrients play a role in regulating GHR expression (Bertucci et al., 2019). Collectively, these results indicate that $\mathrm{GH}$ promotes the gene expression of its receptor to enhance tissue responsiveness to the circulating GH under particular physiological circumstances.
The GI tract has been reported as a major target organ of IGF action (Bortvedt and Lund, 2012). Additionally, a considerable amount of evidence indicates that IGF1 is the main mediator of GH enterotrophic effects (Bortvedt and Lund, 2012; Ge et al., 2015). One of the most prominent effects is the stimulation of intestinal epithelial cell proliferation and maintenance of cell survival by reduction of apoptosis (Kuemmerle, 2012). We also identify a significant increase of igfla mRNA expression in the $g h$-transgenic intestine. Thus, we propose that excess circulating GH can transcriptionally regulate genes related to growth factors in the intestine, such as local production of IGF1 by enterocyte (Ge et al., 2015), to enhance the intestinal length and mass, and consequently improve absorptive plasticity of this tissue to meet the energy demand for accelerated growth. In this sense, Ohneda et al. (1997) demonstrated that the effects of IGF1 overexpression on 
the intestinal length and mucosal mass were similar to the effects of GH overexpression observed in this study.

Phenotypic flexibility of the GI tract in response to changes in demand of organisms has been described in a variety of avian and mammalian species [for a review, refer Starck (2003)] and in fish (Leigh et al., 2017). In this study, we investigate whether the chronic excess of GH could change the intestinal morphology and ultrastructure in the F0104 line. Gh-transgenic zebrafish presented an increase of $8 \%$ in intestinal length and $47 \%$ in intestinal mass with a higher ESI. These findings are in agreement with those described for salmon (Stevens et al., 1999; Stevens and Devlin, 2000, 2005) and mice (Ulshen et al., 1993), which proposed that excess $\mathrm{GH}$ promotes restructuring of the intestinal architecture. A longer intestine means that more digesta can be processed per unit time, which is consistent with higher feed intake (Leigh et al., 2017). Thus, the elongation of the intestine in fish overexpressing GH may be a necessary morphophysiological response to supply the high-energy demand induced by the excess of circulating GH.

In this study, the increase in intestinal mass in $g h$-transgenic zebrafish is due to the increase in the length and width of the intestinal villi and the increase in the height of the enterocytes. This absorption function is increased by the expansion of the intestinal surface from the increase of villi at the tissue level and the increase of microvilli at the cellular level (Wang et al., 2010), and not the cellular apical surface. In humans, villi and microvilli together amplify the small intestinal surface area by 60 120 times (Helander and Fändriks, 2014). Thus, we suggest that overexpression of $g h$ can expand nutrient absorption capacity, extending the intestinal mucosal area, and providing dietary nutrients for growth maintenance.

In this study, we do not identify any difference in the number of intestinal folds and goblet cells or the microvilli surface area between $g h$-transgenic and non-transgenic counterparts. Studies with GH-transgenic salmon have reported an increase in the number of intestinal folds and absorptive surface area in the foregut of transgenic fish (Stevens et al., 1999; Stevens and Devlin, 2000, 2005). In those studies, the methodology used for the morphometric assessment of the intestine differed from the methodology used in the present study. Furthermore, the number or length of the intestinal microvilli was not considered for absorptive surface area calculations. The F0104 $g h$-transgenic zebrafish display larger villi and enterocytes, adjusting to a model of hypertrophy that is less costly from an energy point of view than producing a larger number of cells as reported by Starck (2003). This is likely a strategy to save energy for the maintenance of the intestine itself and to increase the function of this tissue in providing energy for somatic growth.

Among the many functions attributed to $\mathrm{GH}$, its role in protein metabolism is important in the allocation of acquired nutrients toward anabolic processes (Leggatt et al., 2009; Reindl and Sheridan, 2012). In this sense, we analyze whether $g h$ transgenesis can modulate the expression of peptide transport in the intestine. The results show that transcription of slc15a1a and slc15a1b genes, which code for the PEPT1 isoforms, is induced in the intestine of $g h$-transgenic fish. Recently, PetroSakuma et al. (2020) demonstrated that the levels of intestinal pept1a and $-1 b$ transcripts were significantly increased in hypophysectomized tilapia (Oreochromis mossambicus) after GH replacement, indicating that this hormone could stimulate gutspecific transporters that underlie nutrient absorptive capacities. Consistently, the PEPT1 protein has been strongly associated with differentiated and mature absorptive enterocytes (Romano et al., 2014). Additionally, mice lacking intestinal PEPT1 has decreased intestinal uptake and dipeptide permeability (Hu et al., 2008), and also reduced energy intake and differences in the small intestinal morphology, independent of the diet (Kolodziejczak et al., 2013). Taken together, these observations lead us to suggest a potential interaction between enterotrophic effects of the GH-IGF1 system in improving nutrient absorption through transporters such as PEPT1.

Peptide Transporter 1 has emerged as one of the most studied nutrient transport systems in fish, especially due to the strong evidence of its involvement in compensatory growth (Verri et al., 2017). In European sea bass (Dicentrarchus labrax), a carnivorous species, Tevora et al. (Terova et al., 2009) reported a reduction in intestinal PEPT1 expression during fasting followed by an increase during refeeding. In zebrafish, PEPT1 mRNA expression increased approximately eight times higher in refeeding after short-term food deprivation (Koven and Schulte, 2012). These results suggest that this transporter operates directly for fish growth (Verri et al., 2011; Koven and Schulte, 2012). In support of this, when intestinal PEPT1 was inactivated in the nematode Caenorhabditis elegans, animals showed a severely retarded development, reduced progeny, and body size (Meissner et al., 2004). In addition, proteome analysis performed in worms lacking PEPT1 revealed downregulation of ribosomal proteins, leading to impaired ribosome biogenesis and reducing protein de novo synthesis (Geillinger et al., 2014; Spanier and Rohm, 2018). Transport of di or tripeptides involves the same amount of energy as transport of single free amino acids (Daniel, 2004). Also, it has been proven that short peptides are absorbed faster than free amino acids (Ostaszewska et al., 2010a,b). In this context, we suggest that $g h$-transgenic fish have a more efficient peptide transport to meet their metabolic demands and amino acid supply required by support anabolic process. We also hypothesize that the increased expression of PEPT1 in the intestine of $g h$-transgenic zebrafish may be a compensatory effect given that there were no differences in the surface area of the microvilli between the groups.

In fish, as in mammals, energy homeostasis and food intake are regulated by the interaction of central and peripheral (intestine, liver, etc.) endocrine pathways that respond to the energy status of the entire body and requirements (Gorissen et al., 2006; White et al., 2016). Regarding food intake, it has been reported that $g h$-transgenic fish eat much more due to uncontrolled appetite regulation through changes in the $\mathrm{GH}$ axis (Devlin et al., 2001; Raven et al., 2006; Dalmolin et al., 2015; White et al., 2016) and that the intestinal length plus maximum intestinal distension would determine the intake of digestible nutrients and energy (Raven et al., 2006; Leigh et al., 2017). The current study findings for the $g h$-transgenic zebrafish agree 
with the previous studies with respect to their need to satisfy daily energy needs by the significant increase of feed intake relative to non-transgenic counterparts. Moreover, it is well known that intestinal morphology and the overall expression and function of nutrient transporters in enterocytes are triggered by the dietary composition and nutrient supply (Spanier, 2014; Spanier and Rohm, 2018). Therefore, in agreement with Stevens and Devlin (2005), we also believe in the increased intestinal size and absorption capacity of $g h$-transgenic zebrafish as a result of the direct and indirect effects of excess $\mathrm{GH}$.

In the current study, gh-transgenic zebrafish ingested large amounts of protein as a consequence of higher feed intake. Cyprinid culture is one of the largest protein production businesses worldwide and aquaculture is one of the fastestgrowing industrial sectors in the world. Understanding the regulation and functionality of nutrient transporters present in the GI tract of fish can contribute to the development of strategies to increase the commercial production of domesticated fish (Daniel, 2004; Verri et al., 2017; PetroSakuma et al., 2020). In particular, the PEPT1 transporter can be an interesting target for genetic engineering with the objective of developing new fish lines with better use of nutrients present in the feed and, consequently, better growth performance.

In conclusion, this study has added to the understanding of how GH supports somatic growth in a gh-transgenic zebrafish line. Together, the results suggest that $g h$ overexpression stimulates the expression of its receptor in the intestine with a consequent local production of IGF1, which can act directly to increase the mass and absorption area of this organ. In addition, gh-overexpression promotes hyperphagia that provides a greater amount of nutrients in the intestinal lumen and stimulates the synthesis of di-tripeptide transporters, which are the main route of absorption of protein degradation products after a meal. Although the signaling pathway by which $\mathrm{GH}$ regulates amino acids and peptide transporters is still unknown, PEPT1 function can be integrated into the physiological response scheme of the gh-transgenic model to enhance peptide uptake.

\section{REFERENCES}

Abràmo, M. D., Magalhães, P. J., and Ram, S. J. (2004). Image processing with Image J. Biophotonics Inter. 11, 36-42.

Almeida, D. V., Martins, C. M. G., Figueiredo, M. A., Lanes, C. F. C., Bianchini, A., and Marins, L. F. (2013). Growth hormone transgenesis affects osmoregulation and energy metabolism in zebrafish (Danio rerio). Transgenic Res. 22, 75-88. doi: $10.1007 / \mathrm{s} 11248-012-9627-\mathrm{x}$

Batista, C. R., Figueiredo, M. A., Almeida, D. V., Romano, L. A., and Marins, L. F. (2014). Impairment of the immune system in GH-overexpressing transgenic zebrafish (Danio rerio). Fish. Shellfish Immunol. 36, 519-524. doi: 10.1016/j.fsi. 2013.12.022

Bertucci, J. I., Blanco, A. M., Sundarrajan, L., Rajeswari, J., Velasco, C., and Unniappan, S. (2019). Nutrient regulation of endocrine factors influencing feeding and growth in fish. Front. Endocrinol. 10:83. doi: 10.3389/fendo.2019. 00083

\section{DATA AVAILABILITY STATEMENT}

The raw data supporting the conclusions of this article will be made available by the authors, without undue reservation.

\section{ETHICS STATEMENT}

All animal handling procedures were approved by the "Ethics Committee of the Federal University of Rio Grande (FURG)," Protocol number 23116.008403/2018-32.

\section{AUTHOR CONTRIBUTIONS}

$\mathrm{MM}, \mathrm{BN}, \mathrm{TS}$, and MK contributed to the conception and design of the study. MM, BN, TS, MK, CC, and JR developed the experiments and performed statistical analysis. VP and LR helped in the process of standardization and analyses of histological sections. MM, CC, and BN contributed to the pictures design. MM wrote the first draft of the manuscript. LM provided review and editing, project administration, supervision, and funding acquisition. All authors contributed to revising the manuscript, reading, and approving the submitted version.

\section{FUNDING}

MM is a doctoral student financed by Coordenação de Aperfeiçoamento de Pessoal de Nível Superior (CAPES, Finance Code 001). LM and LR are research fellows from Conselho Nacional de Desenvolvimento Científico e Tecnológico (CNPq, Proc. 309634/2018-0 and 304430/2019-6, respectively).

\section{ACKNOWLEDGMENTS}

The authors would like to thank Nara Eliane Moreira Rocha (Laboratório de Imunologia e Microscopia Eletrônica, Embrapa Clima Temperado, EMBRAPA) and the Centro de Microscopia Eletrônica do Sul (CEME-SUL, Universidade Federal do Rio Grande - FURG), Brazil.

Biga, P. R., and Goetz, F. W. (2006). Zebrafish and giant Danio as models for muscle growth: determinate vs. indeterminate growth as determined by morphometric analysis. Am. J. Physiol. Regul. Integr. Comp. Physiol. 291, 1327-1337. doi: 10.1152/ajpregu.00905.2005

Bikhazi, A. B., Skoury, M. M., Zwainy, D. S., Jurjus, A. R., Kreydiyyeh, S. I., Smith, D. E., et al. (2004). Effect of diabetes mellitus and insulin on the regulation of the PepT 1 symporter in rat jejunum. Mol. Pharm. 1, 300-308. doi: 10.1021/ mp049972u

Bortvedt, S. F., and Lund, P. K. (2012). Insulin-like growth factor 1: common mediator of multiple enterotrophic hormones and growth factors. Curr. Opin. Gastroenterol. 28, 89-98. doi: 10.1097/MOG.0b013e32835004c6

Brugman, S. (2016). The zebrafish as a model to study intestinal inflammation. Dev. Comp. Immunol. 64, 82-92. doi: 10.1016/j.dci.2016.02.020

Collie, N. L., and Stevens, J. J. (1985). Hormonal effects on L-proline transport in coho salmon (Oncorhynchus kisutch) intestine. Gen. Comp. Endocrinol. 59, 399-409. doi: 10.1016/0016-6480(85)90397-1 
Dalmolin, C., Almeida, D. V., Figueiredo, M. A., and Marins, L. F. (2015). Food intake and appetite control in a GH-transgenic zebrafish. Fish Physiol. Biochem. 41, 1131-1141. doi: 10.1007/s10695-015-0074-5

Daniel, H. (2004). Molecular and integrative physiology of intestinal peptide transport. Annu. ver. Physiol. 66, 361-384. doi: 10.1146/annurev.physiol.66. 032102.144149

Devlin, R., Johnsson, J., Smailus, D., Biagi, C., Jönsson, E., and Björnsson, B. T. (2001). Increased ability to compete for food by growth hormone-transgenic coho salmon Oncorhynchus kisutch (Walbaum). Aquac. Res. 30, 479-482. doi: 10.1046/j.1365-2109.1999.00359.x

Di Prinzio, C. M., Botta, P. E., Barriga, E. H., Ríos, E. A., Reyes, A. E., and Arranz, S. E. (2010). Growth hormone receptors in zebrafish (Danio rerio): adult and embryonic expression patterns. Gene. Expr. Patterns 10, 214-225. doi: 10.1016/j.gep.2010.03.001

Faccioli, C. K., Chedid, R. A., Mori, R. H., Amaral, A. C., Vicentini, I. B., and Vicentini, C. A. (2016). Ultrastructure of the digestive tract in neotropical carnivorous catfish Hemisorubim platyrhynchos (Valenciennes, 1840) (Siluriformes, Pimelodidae). Scanning 38, 336-343. doi: 10.1002/sca. 21275

Farmanfarmaian, A., and Sun, L. Z. (1999). Growth hormone effects on essential amino acid absorption, muscle amino acid profile, N-retention and nutritional requirements of striped bass hybrids. Genet. Anal. Biomol. Eng. 15, 107-113. doi: 10.1016/S1050-3862(99)00012-1

Figueiredo, M. A., Fernandes, R. V., Studzinski, A. L., Rosa, C. E., Corcini, C. D., Varela Junior, A. S., et al. (2013). GH overexpression decreases spermatic parameters and repro- ductive success in two-years-old transgenic zebrafish males. Anim. Reprod. Sci. 139, 162-167. doi: 10.1016/j.anireprosci.2013.03. 012

Figueiredo, M. A., Lanes, C. F. C., Almeida, D. V., and Marins, L. F. (2007). Improving the production of transgenic fish germline: in vivo mosaicism evaluation by GFP transgene co-injection strategy. Genet. Mol. Biol. 30, 31-36. doi: 10.1590/S1415-47572007000100008

Fuentes, E., Poblete, E., Reyes, A. E., Vera, M. I., Alvarez, M., and Molina, A. (2008). Dynamic expression pattern of the growth hormone receptor during early development of the Chilean flounder. Comp. Biochem. Physiol. B Biochem. Mol. Biol. 150, 93-102. doi: 10.1016/j.cbpb.2008.01.009

Fuentes, E. N., Valdés, J. A., Molina, A., and Björnsson, B. T. (2013). Regulation of skeletal muscle growth in fish by the growth hormone-insulin-like growth factor system. Gen. Comp. Endocrinol. 192, 136-148. doi: 10.1016/j.ygcen.2013. 06.009

Ge, R. T., Mo, L. H., Wu, R., Liu, J. Q., Zhang, H. P., Liu, Z., et al. (2015). Insulin-like growth factor-1 endues monocytes with immune suppressive ability to inhibit inflammation in the intestine. Sci. Rep. 15:7735. doi: 10.1038/srep0 7735

Geillinger, K. E., Kuhlmann, K., Eisenacher, M., Giesbertz, P., Meyer, H. E., Daniel, H., et al. (2014). Intestinal amino acid availability via PEPT-1 affects TORC1/2 signaling and the unfolded protein response. J. Proteome Res. 13, 3685-3692. doi: $10.1021 /$ pr5002669

Gorissen, M., Flik, G., and Huising, M. O. (2006). Peptides and proteins regulating food intake: a comparative view. Anim. Biol. Leiden 56, 447-474. doi: 10.1163/ 157075606778967829

Helander, H. F., and Fändriks, L. (2014). Surface area of the digestive tractrevisited. Scand. J. Gastroenterol. 49, 681-689. doi: 10.3109/00365521.2014.898 326

Hu, Y., Smith, D. E., Ma, K., Jappar, D., Thomas, W., and Hillgren, K. M. (2008). Targeted disruption of peptide transporter Peptl gene in mice significantly reduces dipeptide absorption in intestine. Mol. Pharm. 5, 1122-1130. doi: 10. $1021 / \mathrm{mp} 8001655$

Jia, S. C., Li, X. Y., Zheng, S. X., and Wu, G. (2017). Amino acids are major energy substrates for tissues of hybrid striped bass and zebrafish. Amino Acids 49, 2053-2063. doi: 10.1007/s00726-017-2481-7

Jiao, B., Huang, X., Chan, C. B., Zhang, L., Wang, D., and Cheng, C. H. (2006). The co-existence of two growth hormone receptors in teleost fish and their differential signal transduction, tissue distribution and hormonal regulation of expression in seabream. J. Mol. Endocrinol. 36, 23-40. doi: 10.1677/jme.1. 01945

Kolodziejczak, D., Spanier, B., Pais, R., Kraiczy, J., Stelzl, T., Gedrich, K., et al. (2013). Mice lacking the intestinal peptide transporter display reduced energy intake and a subtle maldigestion/malabsorption that protects them from dietinduced obesity. Am. J. Physiol. Gastrointest. Liver Physiol. 304, G897-G907. doi: 10.1152/ajpgi.00160.2012

Koven, W., and Schulte, P. (2012). The effect of fasting and refeeding on mRNA expression of PepT1 and gastrointestinal hormones regulating digestion and food intake in zebrafish (Danio rerio). Fish Physiol. Biochem. 38, 1565-1575. doi: 10.1007/s10695-012-9649-6

Kuemmerle, J. F. (2012). Insulin-like growth factors in the gastrointestinal tract and liver. Endocrinol. Metab. Clin. North Am. 41, 409-423. doi: 10.1016/j.ecl.2012. 04.018

Kuradomi, R. Y., Figueiredo, M. A., Lanes, C. F. C., Rosa, C. E., Almeida, D. V., Maggioni, R., et al. (2011). GH overexpression causes muscle hypertrophy independent from local IGF-I in a zebrafish transgenic model. Transgenic Res. 20, 513-521. doi: 10.1007/s11248-010-9429-y

Leggatt, R., Raven, P., Mommsen, T., Sakhrani, D., Higgs, D., and Devlin, R. (2009). Growth hormone transgenesis influences carbohydrate, lipid and protein metabolism capacity for energy production in coho salmon (Oncorhynchus kisutch). Comp. Biochem. Physiol. B Biochem. Mol. Biol. 154, 121-133. doi: 10.1016/j.cbpb.2009.05.010

Leigh, S. C., Nguyen-Phuc, B. Q., and German, D. P. (2017). The effects of protein and fiber content on gut structure and function in zebrafish (Danio rerio). J. Comp. Physiol. B 188, 237-253. doi: 10.1007/s00360-017-1122-5

Li, Y., Liu, X., Zhang, Y., Zhu, P., and Lin, H. (2007). Molecular cloning, characterization and distribution of two types of growth hormone receptor in orange-spotted grouper (Epinephelus coioides). Gen. Comp. Endocrinol. 152, 111-122. doi: 10.1016/j.ygcen.2007.01.033

Løkka, G., Austbø, L., Falk, K., Bjerkå, I., and Koppang, E. O. (2013). Intestinal morphology of the wild atlantic salmon (Salmo salar). J. Morphol. 274, 859-876. doi: 10.1002/jmor.20142

Lu, M., Flanagan, J. U., Langley, R. J., Hay, M. P., and Perry, J. K. (2019). Targeting growth hormone function: strategies and therapeutic applications. Sig. Transduct. Target. Ther. 4:3. doi: 10.1038/s41392-019-0036-y

McConnell, R. E., Benesh, A. E., Mao, S., Tabb, D. L., and Tyska, M. J. (2011). Proteomic analysis of the enterocyte brush border. Am. J. Physiol. Liver Physiol. 300, G914-G926. doi: 10.1152/ajpgi.00005.2011

Meissner, B., Boll, M., Daniel, H., and Baumeister, R. (2004). Deletion of the intestinal peptide transporter affects insulin and TOR signalling in Caenorhabditis elegans. J. Biol. Chem. 279, 36739-36745. doi: 10.1074/jbc. M403415200

Mommsen, T. P. (2001). Paradigms of growth in fish. Comp. Biochem. Physiol. B Biochem. Mol. Biol. 129, 207-219. doi: 10.1016/S1096-4959(01)00312-8

Ohneda, K., Ulshen, M. H., Fuller, C. R., Dércole, A. J., and Lund, P. K. (1997). Enhanced growth of small bowel in transgenic mice expressing human insulinlike growth factor I. Gastroenterology 112, 444-454. doi: 10.1053/gast.1997. v112.pm9024298

Ostaszewska, T., Dabrowski, K., Kamaszewski, M., Grochowski, P., Verri, T., Rzepkowska, M., et al. (2010a). The effect of plant protein-based diet supplemented with dipeptide or free amino acids on digestive tract morphology and PepT1 and PepT2 expressions in common carp (Cyprinus carpio L.). Comp. Biochem. Physiol. A Mol. Integr. Physiol. 157, 158-169. doi: 10.1016/j.cbpa.2010. 06.162

Ostaszewska, T., Kamaszewski, M., Grochowski, P., Dabrowski, K., Verri, T., Aksakal, E., et al. (2010b). The effect of peptide absorption on PepT1 gene expression and digestive system hormones in rainbow trout (Oncorhynchus mykiss). Comp. Biochem. Physiol. A Mol. Integr. Physiol. 155, 107-114. doi: 10.1016/j.cbpa.2009.10.017

Petro-Sakuma, C., Celino-Brady, F. T., Breves, J. P., and Seale, A. P. (2020). Growth hormone regulates intestinal gene expression of nutrient transporters in tilapia (Oreochromis mossambicus). Gen. Comp. Endocrinol. 292:113464. doi: 10.1016/ j.ygcen.2020.113464

Pfaffl, M. W. (2001). A new mathematical model for relative quantification in real-time RT- PCR. Nucleic Acids Res. 29:e45. doi: 10.1093/nar/29.9.e45

Ranke, M. B., and Wit, J. M. (2018). Growth hormone-past, present and future. Nat. Rev. Endocrinol. 14, 285-300. doi: 10.1038/nrendo.2018.22

Rassier, G. T., Silveira, T. L. R., Remião, M. H., Daneluz, L. O., Martins, A. W. S., Dellagostin, E. N., et al. (2020). Evaluation of qPCR reference genes in GHoverexpressing transgenic zebrafish (Danio rerio). Sci. Rep. 10:12692. doi: 10. 1038/s41598-020-69423-y 
Raven, P. A., Devlin, R. H., and Higgs, D. A. (2006). Influence of dietary digestible energy content on growth, protein and energy utilization and body composition of growth hormone transgenic and non-transgenic coho salmon (Oncorhynchus kisutch). Aquaculture 254, 730-747. doi: 10.1016/j.aquaculture.2005.11.009

Reindl, K. M., and Sheridan, M. A. (2012). Peripheral regulation of the growth hormone- insulin-like growth factor system in fish and other vertebrates. Comp. Biochem. Physiol. A Mol. Integr. Physiol. 163, 231-245. doi: 10.1016/j.cbpa.2012. 08.003

Romano, A., Barca, A., Storelli, C., and Verri, T. (2014). Teleost fish models in membrane transport research: the PEPT1(SLC15A1) H+- oligopeptide transporter as a case study. J. Physiol. 592, 881-897. doi: 10.1113/jphysiol.2013. 259622

Rosa, C. E., Figueiredo, M. A., Lanes, C. F. C., Almeida, D. V., and Marins, L. F. (2011). Genotype-dependent gene expression profile of the antioxidant defense system (ADS) in the liver of a GH-transgenic zebrafish model. Transgenic Res. 20, 85-89. doi: 10.1007/s11248-010-9395-4

Rosa, C. E., Figueiredo, M. A., Lanes, C. F. C., Almeida, D. V., Monserrat, J. M., and Marins, L. F. (2008). Metabolic rate and reactive oxygen species production in different genotypes of GH-transgenic zebrafish. Comp. Biochem. Physiol. B Biochem. Mol. Biol. 149, 209-214. doi: 10.1016/j.cbpb.2007.0 9.010

Rosa, C. E., Kuradomi, R. Y., Almeida, D. V., Lanes, C. F. C., Figueiredo, M. A., Dytz, A. G., et al. (2010). GH overexpression modifies muscle expression of antioxidant enzymes and increases spinal curvature of old zebrafish. Exp. Gerontol. 45, 449-456. doi: 10.1016/j.exger.2010.03.012

Rubio-Aliaga, I., and Daniel, H. (2008). Peptide transporters and their roles in physiological processes and drug disposition. Xenobiotica 38, 1022-1042. doi: 10.1080/00498250701875254

Silva, A. C. G., Almeida, D. V., Nornberg, B. F., Figueiredo, M. A., Romano, L. A., Marins, L. F., et al. (2015). Effects of double transgenesis of somatotrophic axis (GH/GHR) on skeletal muscle growth of zebrafish (Danio rerio). Zebrafish 12 , 408-413. doi: 10.1089/zeb.2015.29001.sil

Spanier, B. (2014). Transcriptional and functional regulation of the intestinal peptide transporter PEPT1. J. Physiol. 592, 871-879. doi: 10.1113/jphysiol.2013. 258889

Spanier, B., and Rohm, F. (2018). Proton coupled oligopeptide transporter 1 (PepT1) function, regulation, and influence on the intestinal homeostasis. Compr. Physiol. 8, 843-869. doi: 10.1002/cphy.c170038

Starck, J. M. (2003). Shaping up: how vertebrates adjust their digestive system to changing environmental conditions. Anim. Biol. J. 53, 245-257. doi: 10.1163/ 157075603322539444

Stevens, E. D., and Devlin, R. H. (2000). Intestinal morphology in growth hormone transgenic coho salmon. J. Fish. Biol. 56, 191-195. doi: 10.1111/j.1095-8649. 2000.tb02094.x

Stevens, E. D., and Devlin, R. H. (2005). Gut size in GH-transgenic coho salmon is enhanced by both the GH transgene and increased food intake. J. Fish. Biol. 66, 1633-1648. doi: 10.1111/j.0022-1112.2005.00707.x

Stevens, E. D., Wagner, G. N., and Sutterlin, A. M. (1999). Gut morphology in growth hormone transgenic Atlantic salmon. J. Fish. Biol. 55, 517-526. doi: 10.1111/j.10958649.1999.tb00696.x

Sun, L.-Z., and Farmanfarmaian, A. (1992). Biphasic action of growth hormone on intestinal amino acid absorption in striped bass hybrids. Comp. Biochem. Physiol. A Comp. Physiol. 103, 381-390. doi: 10.1016/0300-9629(92)90598-K

Tavernier, A., Cavin, J. B., Le Gall, M., Ducroc, R., Denis, R. G., Cluzeaud, F., et al. (2014). Intestinal deletion of leptin signaling alters activity of nutrient transporters and delayed the onset of obesity in mice. FASEB J. 28, 4100-4110. doi: 10.1096/fj.14-255158

Terova, G., Corà, S., Verri, T., Rimoldi, S., Bernardini, G., and Saroglia, M. (2009). Impact of feed availability on PepT1 mRNA expression levels in sea bass (Dicentrarchus labrax). Aquaculture 294, 288-299. doi: 10.1016/j.aquaculture. 2009.06.014
Ulshen, M. H., Dowling, R. H., Fuller, C. R., Zimmermann, E. M., and Lund, P. K. (1993). Enhanced growth of small bowel in transgenic mice overexpressing bovine growth hormone. Gastroenterology 104, 973-980. doi: 10.1016/00165085(93)90263-c

Vacca, F., Barca, A., Gomes, A. S., Mazzei, A., Piccinni, B., Cinquetti, R., et al. (2019). The peptide transporter la of the zebrafish Danio rerio, an emerging model in nutrigenomics and nutrition research: molecular characterization, functional properties, and expression analysis. BMC Genes Nutr. 14:33. doi: 10.1186/s12263-019-0657-3

Van Waarde, A. (1983). Aerobic and anaerobic ammonia production by fish. Comp. Biochem. Physiol. B 74, 675-684. doi: 10.1016/0305-0491(83)90127-X

Vandesompele, J., De Preter, K., Pattyn, F., Poppe, B., Van Roy, N., De Paepe, A., et al. (2002). Accurate normalization of real-time quantitative RT-PCR data by geometric averaging of multiple internal control genes. Genome Biol. 3, research0034. doi: 10.1186/gb-2002-3-7-research0034

Verri, T., Barca, A., Pisani, P., Piccinni, B., Storelli, C., and Romano, A. (2017). Diand tripeptide transport in vertebrates: the contribution of teleost fish models. J. Comp. Physiol. B 187, 395-462. doi: 10.1007/s00360-016-1044-7

Verri, T., Kottra, G., Romano, A., Tiso, N., Peric, M., Maffia, M., et al. (2003). Molecular and functional characterization of the zebrafish (Danio rerio) PEPT1- type peptide transporter. FEBS Lett. 549, 115-122. doi: 10.1016/S00145793(03)00759-2

Verri, T., Terova, G., Dabrowski, K., and Saroglia, M. (2011). Peptide transport and animal growth: the fish paradigm. Biol. Lett. 7, 597-600. doi: 10.1098/rsbl.2010. 1164

Walker, R. L., Buret, A. G., Jackson, C. L., Scott, K. G. E., Bajwa, R., and Habibi, H. R. (2004). Effects of growth hormone on leucine absorption, intestinal morphology, and ultrastructure of the goldfish intestine. Can. J. Physiol. Pharmacol. 82, 951-959. doi: 10.1139/y04103

Wang, Z., Du, J., Siew, H. L., Sinnakarupan, M., Matsudaira, P., and Gong, Z. (2010). Morphological and molecular evidence for functional organization along the rostrocaudal axis of the adult zebrafish intestine. BMC Genomics 11:391. doi: 10.1186/1471-2164-11-392

White, S. L., Volkoff, H., and Devlin, R. H. (2016). Regulation of feeding behavior and food intake by appetite-regulating peptides in wild-type and growth hormone-transgenic coho salmon. Horm. Behav. 84, 18-28. doi: 10.1016/j. yhbeh.2016.04.005

Zeng, L. Q., Fu, S. J., Li, X. M., Li, F. J., Li, B., Cao, Z. D., et al. (2014). Physiological and morphological responses to the first bout of refeeding in southern catfish (Silurus meridionalis). J. Comp. Physiol. B 184, 329-346. doi: 10.1007/s00360014-0801-8

Conflict of Interest: The authors declare that the research was conducted in the absence of any commercial or financial relationships that could be construed as a potential conflict of interest.

Publisher's Note: All claims expressed in this article are solely those of the authors and do not necessarily represent those of their affiliated organizations, or those of the publisher, the editors and the reviewers. Any product that may be evaluated in this article, or claim that may be made by its manufacturer, is not guaranteed or endorsed by the publisher.

Copyright (c) 2021 Meirelles, Nornberg, da Silveira, Kütter, Castro, Ramirez, Pedrosa, Romano and Marins. This is an open-access article distributed under the terms of the Creative Commons Attribution License (CC BY). The use, distribution or reproduction in other forums is permitted, provided the original author(s) and the copyright owner(s) are credited and that the original publication in this journal is cited, in accordance with accepted academic practice. No use, distribution or reproduction is permitted which does not comply with these terms. 